\title{
Polymorphisms of Vitamin D Receptor and the Effect on Metabolic and Endocrine Abnormalities in Polycystic Ovary Syndrome: A Review
}

Authors

Talida Vulcan ${ }^{1}$, Gabriela Adriana Filip ${ }^{2}$, , Lavinia Manuela Lenghel ${ }^{3}$, Tudor Suciu ${ }^{4}$, Paula Ilut ${ }^{1}$, Lucia Maria Procopciuc ${ }^{5}$

Affiliations

1 Iuliu Hatieganu University of Medicine and Pharmacy Faculty of Medicine, Dermatology Cluj Napoca, Romania

2 Iuliu Hatieganu University of Medicine and Pharmacy Faculty of Medicine, Physiology Cluj Napoca, Romania

3 Iuliu Hatieganu University of Medicine and Pharmacy Faculty of Medicine, Radiology, Cluj Napoca, Romania

4 Iuliu Hatieganu University of Medicine and Pharmacy Faculty of Medicine, Maxillofacial Surgery and Radiology, Cluj Napoca, Romania

5 Iuliu Hatieganu University of Medicine and Pharmacy Faculty of Medicine, Medical Biochemistry, Cluj Napoca, Romania

Key words vitamin D receptor polymorphism, PCOS, hyperandrogenism, insulin resistance

received 22.02.2021

accepted after revision $\quad 07.06 .2021$

published online 20.09.2021

\section{Bibliography}

Horm Metab Res 2021; 53: 645-653

DOI 10.1055/a-1587-9336

ISSN 0018-5043

(c) 2021. Thieme. All rights reserved.

Georg Thieme Verlag, Rüdigerstraße 14,

70469 Stuttgart, Germany

\author{
Correspondence \\ Gabriela Adriana Filip \\ Iuliu Hatieganu University of Medicine and Pharmacy Faculty \\ of Medicine, Physiology \\ Barsei no 1/17 Cluj Napoca \\ 400349 Cluj Napoca \\ Romania \\ Tel.: + 40745268704 \\ adrianafilip33@yahoo.com
}

\section{ABSTRACT}

Polycystic ovary syndrome (PCOS) is one of the most prevalent endocrine disorder in women of reproductive age. Vitamin D and its receptor are thought to play an important role in PCOS susceptibility, although the impact of vitamin D receptor (VDR) polymorphisms on the hormonal and metabolic profile is still controversial. A literature search in PubMed and Embase was performed up to September 2020 for case-control studies in women suffering from PCOS, with outcome related to VDR polymorphisms effect on metabolic/endocrine disturbances. We have found 16 eligible studies including 2566 women with PCOS and 2430 controls. Apal polymorphism seemed to be associated with hyperandrogenism in both Asian and Caucasian population. Fokl variant was correlated with metabolic/endocrine parameters especially in Asian population, while a relation between $C d \times 2$ genotypes and insulin sensitivity was observed in both ethnicities. VDR polymorphisms have an important role in PCOS development and related hormonal and metabolic abnormalities. Few case-control studies analysed the interaction between VDR variants and metabolic/endocrine parameters with the majority of the articles focused on the Asian region. Further research on various ethnic populations with larger sample size are still needed for a definitive conclusion, in order to allow early diagnosis and prevention of PCOS Comorbidities.

\section{Introduction}

Polycystic ovary syndrome (PCOS) is a highly prevalent disorder among women of reproductive age, with a wide range of signs and symptoms, accompanied by a high risk of metabolic and cardiovascular diseases. It is a heterogeneous condition characterized by hyperandrogenism (HA), ovulatory dysfunction and polycystic ovar- ian morphology [1] affecting 4-21\% of women worldwide depending on the diagnostic criteria used [2]. The Rotterdam criteria are internationally accepted and require the presence of two of the three findings: clinical/biochemical HA, chronic ovulatory dysfunction and polycystic ovarian morphology at ultrasound examination, after exclusion of secondary causes [3]. National Institutes of 
Health $(\mathrm{NIH})$ criteria confirm the diagnosis in the presence of clinical/biochemical HA and ovulatory dysfunction $[3,4]$ this set of criteria still being in use in literature reports.

The etiology of PCOS is multifactorial and not fully understood. Some of the main known mechanisms to date are represented by alteration in the secretion of gonadotropin-releasing hormone, defects in androgen synthesis, development of insulin resistance (IR) and ovarian follicular arrest [5].

Disturbances of the hypothalamic-pituitary axis determine elevated levels of luteinizing hormone (LH) and normal/low levels of follicle stimulating hormone (FSH), due to a higher frequency of gonadotropin-releasing hormone pulses [6]. LH stimulates androgen production and interferes with normal follicular development [5].

IR is one of the key components in this complex disorder. IR with compensatory hyperinsulinemia (HI) determine HA by acting synergically with LH on ovarian steroidogenesis. Moreover, by inhibiting the liver synthesis of sex hormone binding globulin it increases testosterone availability [7]. HI increases risk for type 2 diabetes, hypertension, endothelial dysfunction, atherosclerosis, and cardiovascular diseases [6]. HI and HA can disrupt follicle growth, accompanied by menstrual irregularity and accumulation of immature follicles ( $\triangleright$ Fig. 1). In addition, higher levels of anti-Müllerian hormone (AMH) are a result of increased number of small antral follicles [1], impairing the follicle growth and the selection of a dominant follicle [8].

The clinical manifestations are consecutive to androgen excess, which lead to dermatological and gynecological disturbances. Specific cutaneous features include hirsutism, acne, seborrhea, androgenic alopecia, and acanthosis nigricans. Hirsutism is used as an indicator of $\mathrm{HA}$, being in some studies reported as the most common skin manifestation in PCOS and closely related to metabolic abnormalities [9]. Acanthosis nigricans is a known marker of $\mathrm{HI}$, while obesity is independently associated with it $[10,11]$.

The phenotypic classification allows a better characterization the syndrome: phenotype A: androgen excess, ovulatory dysfunction and polycystic ovarian morphology; phenotype B: androgen excess and ovulatory dysfunction; phenotype $C$ : androgen excess and polycystic ovarian morphology; and phenotype D: ovulatory dysfunction and polycystic ovarian morphology [12]. Different phenotypes were observed to be predominant in various populations. PCOS also determines anovulatory infertility in $70 \%$ of women, being the most common cause of ovulatory dysfunction [12].

\section{Vitamin D and PCOS}

Vitamin $D$ (vit $D$ ) is a steroid hormone, synthesized mainly by the skin under ultraviolet type $B$ radiation, while food sources contribute in small part to its circulating levels [13]. Beside its well-known role in maintaining calcium homeostasis and bone mineralization [14], vit D has anti-inflammatory, antioxidant, immunomodulatory, antiangiogenic, and antiproliferative proprieties [15] (• Fig. 2). Accumulating evidence suggest that vit $D$ status has a close association with the pathogenesis of IR and metabolic syndrome in PCOS [16]. Despite the thoroughly studied relation between vit D level and PCOS per se, the results are still controversial. It seems that most of the connections are between vit $D$ receptor polymorphism and PCOS.

\section{Vitamin D receptor polymorphisms}

Vit $\mathrm{D}$ biological actions in different tissues are mediated by the vit $D$ receptor (VDR), a ligand-dependent transcription factor of steroid/thyroid hormone receptor super family, which regulates $~ 3 \%$ of the human genome [17]. By binding to VDR, vit D generates the transcription of vit $D$ related genes [18].

VDR gene is located on chromosome 12q13, it contains 14 exons [19] and covers over $75 \mathrm{~kb}$ of genomic DNA. It is formed by two promoter regions, eight protein coding exons (2-9) and six untranslated exons (1a-1 f) [20]. The gene is highly polymorphic and many allelic variants due to single nucleotide polymorphisms have been reported, which are variable among different ethnic groups $[20,21]$.

The most studied VDR polymorphisms related to PCOS are represented by: Fokl (CC:CT:TT genotypes, C:T alleles), Bsml (AA:AG:GG genotypes, A:G alleles), Apal (AA:AC:CC genotypes, A:C alleles), Taql (TT:TC:CC genotypes, T:C alleles), Tru9I (GG:GA:AA genotypes, G:A alleles), and Cdx2 (GG:GA:AA genotypes, G:A allele).

Over the past decade, researchers focused on several candidate genes involved in steroidogenesis, insulin signaling pathway, gonadotropin secretion [22] or vitamin D metabolism, in the attempt to increase knowledge about PCOS pathogenesis.

The results obtained so far are inconsistent; therefore, the aim of this review is to examine the association between VDR polymorphisms and metabolic or endocrine disturbances in women with PCOS, in different ethnic groups.

\section{Materials and Methods}

Two databases (PubMed and Embase) were searched up to September 2020 for original case-control studies that investigated the association between VDR polymorphisms and endocrine or metabolic parameters in PCOS. The search strategy included the following keywords in all possible combinations: PCOS OR polycystic ovary syndrome and VDR OR vitamin D receptor polymorphism; PCOS OR polycystic ovary syndrome and Bsml, Apal, Fokl, Taql, Cdx2, Tru9I. The references of the included studies were also searched manually to find additional publications potentially missed.

Studies were chosen if they met the following criteria: 1) published studies in English; 2) studies reporting evidence in humans only; 3 ) inclusion of women with PCOS and a control group; 4) inclusion of at least one of the following VDR polymorphisms-Fokl, Bsml, Apal, Taql, Cdx2, Tru9l and their correlation with at least one metabolic or endocrine parameter as the main outcome; and 5) PCOS defined by Rotterdam or NIH criteria. We excluded case reports, editorials, reviews, conference abstracts, duplicates, or studies in other language than English (see flow chart, > Fig. 3). The following information was extracted from each included study: name of the first author, ethnicity, selection criteria, number of participants, studied polymorphism and the main outcome ( Table 1). 


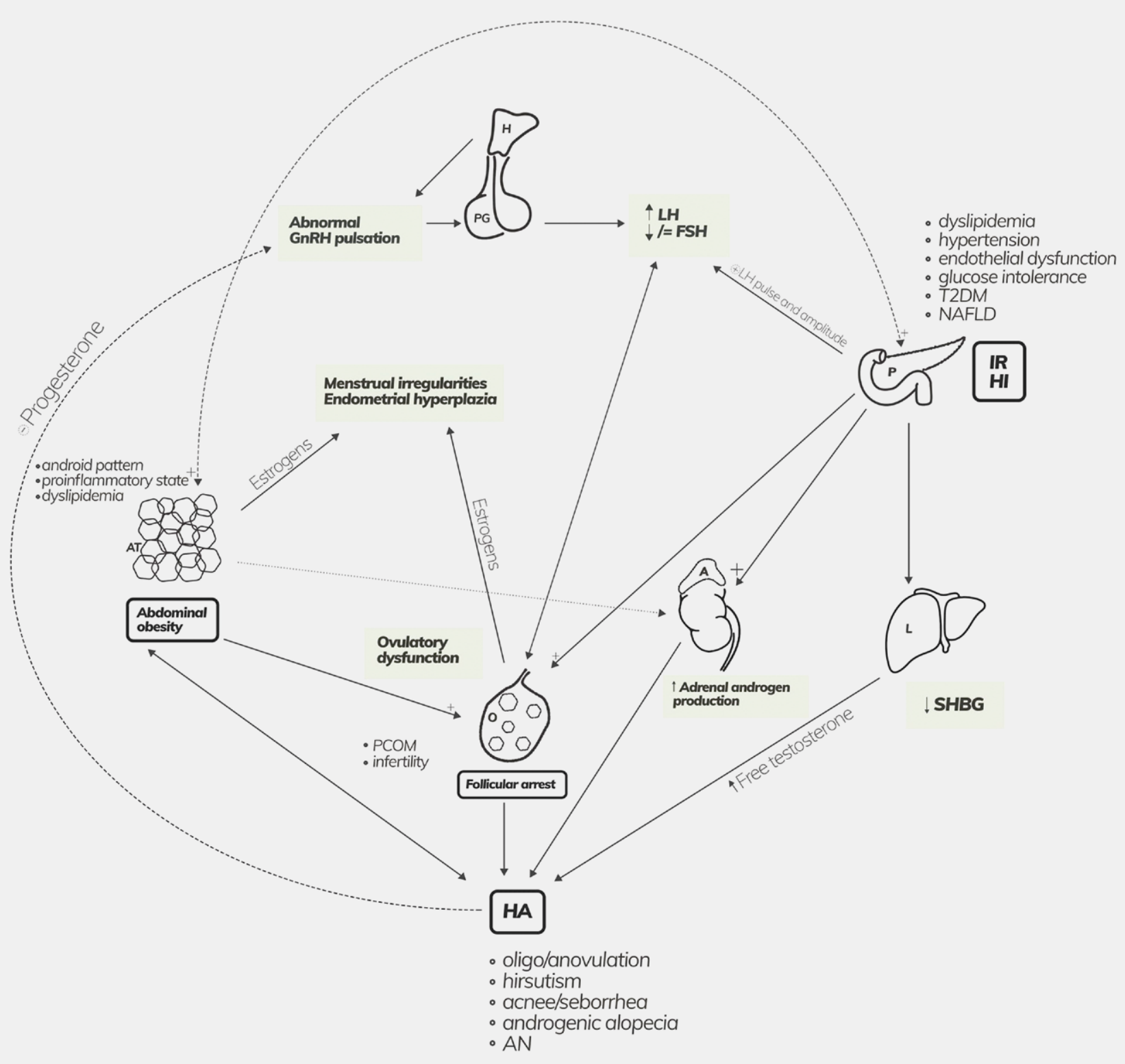

- Fig. 1 Schematic representation of the mechanisms interplay in PCOS. Androgen excess facilitates IR and metabolic dysfunction by favoring abdominal and visceral adiposity. Increased estrogen production by ovaries and fat tissue determines menstrual irregularities and risk for endometrial hyperplasia. IR and compensatory HI favor anovulation; HA causes metabolic and cardiovascular complications. PCOS: Polycystic ovary syndrome; IR: Insulin resistance; HI: Hyperinsulinemia; HA: Hyperandrogenism; GnRH: Gonadotrophin releasing hormone; H: Hypothalamus; PG: Pituitary gland; LH: Luteinizing hormone; FSH: Follicle-stimulating hormone; P: Pancreas; L: Liver; SHBG: Sex hormone binding globulin; A: Adrenal gland; O: Ovary; AT: Adipose tissue; T2DM: Type 2 diabetes mellitus; NAFLD: Non-alcoholic fatty liver disease; AN: Acanthosis nigricans; PCOM: Polycystic ovarian morphology.

\section{Results}

\section{PCOS and Fokl polymorphism}

Fokl polymorphism (rs2228570, previously named rs10735810) located on exon 2 of the coding region of VDR gene is a T $\rightarrow C$ transition in the exon. It alters the first translation site, creating a new start codon, modifying the transcriptional activity of the gene, producing an altered protein, containing 427 amino acids instead of 424 amino acids $[23,24]$. Thus, two protein variants can exist, each one corresponding to the site where the translation starts from: a long version (the "f" allele) and the shortened version by 3 amino acids (the "F" allele) [25].

VDR Fokl "AC" genotype was reported to be significantly associated with increased levels of testosterone [18]. On the other hand, Wehr et al. showed no association of VDR Fokl polymorphisms with anthropometric, endocrine and metabolic parameters, in a study involving Caucasian women with PCOS [16]. 


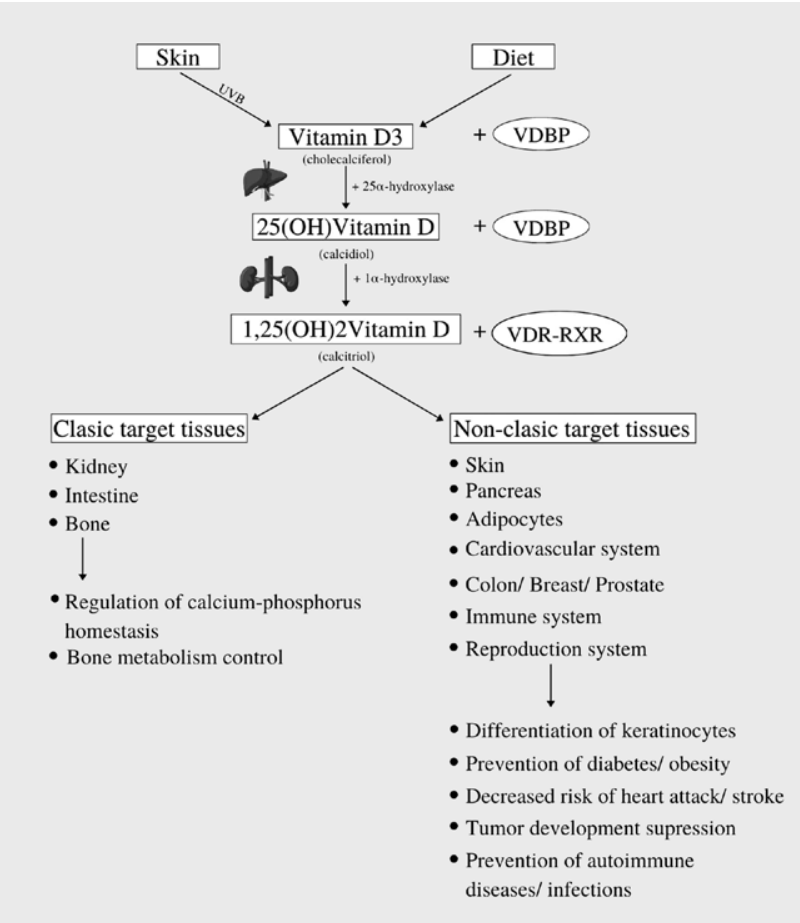

- Fig. 2 Vitamin D action in classic and non-classic target tissues. Vitamin $\mathrm{D}$ circulates bound to plasma vitamin $\mathrm{D}$ binding protein (VDBP) to the liver and kidney for metabolic activation. The active form binds to vitamin $D$ receptor-retinoid $X$ receptor heterodimer (VDR-RXR), which is widely distributed throughout tissues in order to exert its functions.

Previously, in 2009 Mahmoudi et al. found that subjects with the "FF" genotype had increased risk for abnormal serum insulin levels and IR than those with the "Ff/ff" genotypes [26], while another study reported that Indian women with "TT" genotype presented increased risk for infertility, acne, alopecia and elevated cholesterol levels [27]. In a small study carried on 33 Saudi women, weight, vit D, LH were higher in PCOS group. Interestingly, a positive correlation was found between the level of vit D and FSH, but only in the control group [21]. In a study carried on obese PCOS women in Western Asia, both Fokl "FF" and Apal "AA" genotypes showed lower levels of androstenedione and vit $D$ status [28].

When analyzing the classic PCOS phenotype, higher waist circumference and android to gynoid fat deposit ratio were observed, but also higher levels of serum fasting glucose, insulin, triglycerides and testosterone. Sex hormone binding globulin levels were lower compared to healthy controls. Regarding the genotype frequencies, there was no variation between groups. Moreover, no difference was observed between Fokl genotypes and metabolic or anthropometric parameters [29].

$\mathrm{AMH}$ is a good marker for determining the ovarian reserve. Szafarowska and co-workers examined the influence of vit $D$ and VDR polymorphisms on AMH levels, which were higher in PCOS group, while vit $D$ levels were lower. Only Fokl and Apal heterozygous or mutant genes had a significant correlation with $A M H$ values, while Apal "AA" type presented higher vit D levels [30].

\section{PCOS and Apal polymorphism}

Apal polymorphism (rs7975232) is located in intron 8 at the 3rd end of the VDR gene. The 3'-UTR (untranslated) region is involved in mRNA stability and post-transcriptional processes [17]. The results about Apal polymorphism and the association with PCOS are contradictory, mainly because it does not alter the amino acid sequence, but it is involved in regulation of the gene's expression [23]. A recent meta-analysis confirmed the association between Apal and PCOS risk, highlighting the individual differences in susceptibility to PCOS: variant "aa" offers susceptibility to PCOS in Asian population, while Apal "a" and "aa + Aa" haplotype offer increased risk in Caucasian women [15].

Thirteen of the reviewed studies determined VDR gene Apal polymorphism, but only in 6 of them have we found significant correlations with metabolic/endocrine parameters. Wehr et al. showed that Apal "AA" genotype had lower testosterone levels. No association with metabolic parameters was observed, neither with PCOS susceptibility [16]. On the contrary, Mahmoudi et al. was the first one to show association between VDR Apal and PCOS in Asian subjects: the "aa" genotype was associated with increased risk for PCOS, whereas the "Aa" genotype appeared as a marker of decreased susceptibility [26].

Dasgupta et al. found that "CC" genotype had increased risk for infertility, while heterozygote genotypes showed alopecia and acanthosis traits. Overall, genotype "AA" was associated with elevated testosterone levels, although not significant [27]. Another study carried on Indian women showed that androstenedione levels were significantly higher in Apal "AA" compared to "CC" genotype, while "CC" genotype was associated with lower estradiol levels. Moreover, overweight/obesity was higher in PCOS group alongside with insulin, dehydroepiandrosterone sulfate, 17-hydroxyprogesterone values, whereas vit $D$ mean serum levels were lower [31].

Santos and co-workers investigated metabolic and endocrine abnormalities in a group selected by Rotterdam criteria. The subjects had significantly higher total testosterone and free androgen index values, with lower sex hormone binding globulin levels, but vit $D$ was similar between groups. To notice, in PCOS women lower vit $D$ levels were related to metabolic syndrome and its isolated components: higher glucose, waist circumference and triglycerides. Apal "CC" genotype had a higher risk for metabolic syndrome in PCOS group compared to "CA + AA" genotype and it was also associated with higher systolic blood pressure, total cholesterol and low-density lipoprotein-cholesterol in both groups, suggesting that Apal variant might be correlated with metabolic syndrome in PCOS women [32].

Regarding prolactin levels, Kadhim et al. revealed that Apal "CC" and "CA" genotypes, alongside Fokl "CC" and Taql "CC" genotypes had higher levels of prolactin hormone in PCOS women [33].

\section{PCOS and Bsml polymorphism}

Bsml polymorphism (rs 1544410) is located in intron 8 at the 3rd end of the gene near to Apal. It is known as a silent polymorphism, which does not change the amino acids sequence. Due to its location in the gene, it might be involved in regulation of gene expression through influencing mRNA stability $[24,34]$.

The association between Bsml and PCOS remains to be determined; while some authors consider it is not associated with PCOS 


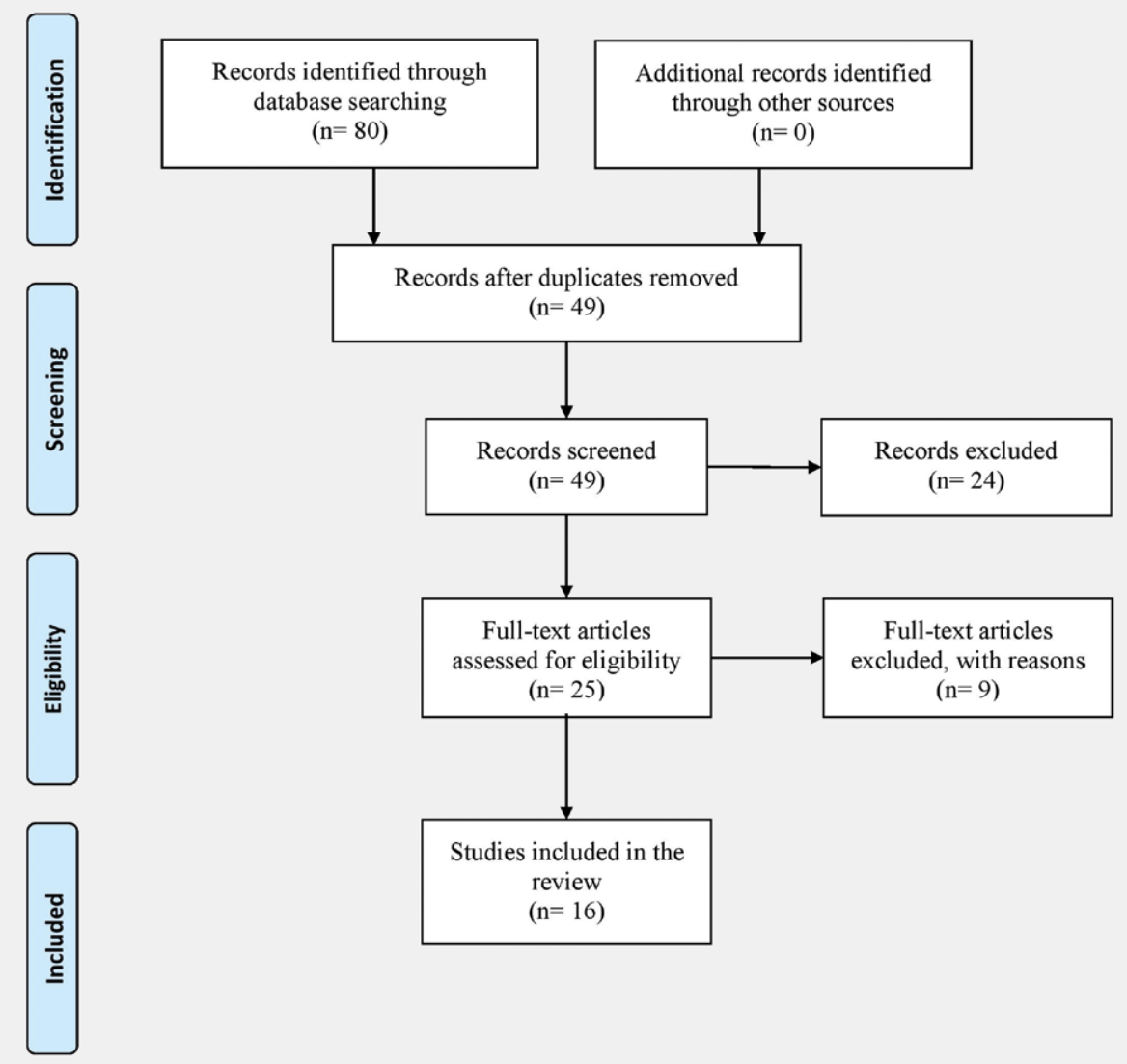

- Fig. 3 Flow chart of the methodology of selection of papers for this review.

susceptibility [35] or endocrine/metabolic parameters [16], others report the other way around [17, 34, 36]. Mahmoudi et al. highlight that Bsml "Bb" genotype appeared to be a marker of decreased PCOS risk [34]. Previously, the same author found that Bsml "bb" and Taql "TT" genotypes had higher vit D serum levels compared to those with "BB/Bb" or "Tt/tt" [26]. The rest of the reports failed to find correlations with endocrine or metabolic parameters [16, 34, 37].

\section{PCOS and Taql polymorphism}

Taql polymorphism (rs 731236) is a restriction fragment length polymorphism located in exon 9 , very close to the 3 '-UTR region [24] that acts especially by modulating mRNA stability without altering the encoded amino acid, generating a synonymous mutation [23]. The majority of the studies confirmed the relationship between Taql polymorphism and PCOS risk [17, 20, 23, 36, 38]. Xavier et al. reported that Taql "CC" type was more frequent in the PCOS group [23], result that is consistent with another study [38]. Dasgupta et al. found that the mean values of FSH, LH and cholesterol were higher for "TC" genotype, while Taql "CC" exhibited the highest mean value of testosterone. Moreover, women with PCOS with "CC" or "CT" genotype were found to be relatively more hirsute [27]. A small study found that the PCOS group had higher vit $D$ and LH levels, while a significant positive correlation was seen be- tween vit D and FSH in control group only. Interestingly, Taql "CC" genotype was associated with vit D level in PCOS group, but not with LH level [21]. Another study carried on Caucasian women found significantly higher values of hirsutism score, cholesterol, triglycerides, fasting blood glucose and insulin, higher LH and androgens levels, alongside with lower sex hormone binding globulin, FSH and vit D values in PCOS group. Prevalence of Taql "CC" genotype and " $C$ " allele were significantly higher, while " $C$ " allele was more frequent in obese women, showing the interaction between Taql genotype and obesity. Moreover, women carrying "CC" and "TC" genotype had higher body mass index, fasting insulin, HOMA-IR (homeostasis model assessment-estimated insulin resistance index), androgen hormones, with lower levels of vit $D$ and Quantitative insulin sensitivity check index (QUICKI) than the homozygous variants for T alleles. The haplotype TaqI C/Apal C was frequent in PCOS group and it was associated with lower levels of vit $D$ and increased levels of androgens. El-Shal et al. also found that vit $D$ levels were negatively correlated with body mass index, cholesterol and triglycerides in both groups, but in PCOS women the levels were decreased when compared with healthy controls. As a particularity of the study, vit D levels were correlated negatively with hirsutism score and Taql polymorphism was an independent risk factor for PCOS [20]. 
> Table 1 Summary data on association between VDR gene polymorphisms and PCOS metabolic/endocrine abnormalities.

\begin{tabular}{|c|c|c|c|c|c|}
\hline Publication & Ethnicity & $\begin{array}{l}\text { Case } \\
\text { selection }\end{array}$ & $\begin{array}{l}\text { Number of } \\
\text { participants }\end{array}$ & Studied SNP & Conclusion \\
\hline $\begin{array}{l}\text { Mahmoudi et al. } \\
\text { (2009) [26] }\end{array}$ & $\begin{array}{l}\text { Western } \\
\text { Asian }\end{array}$ & NIH criteria & $\begin{array}{l}\text { PCOS: } 162 \\
\text { Control: } 162\end{array}$ & $\begin{array}{l}\text { Fokl Apal } \\
\text { Bsml Taql }\end{array}$ & $\begin{array}{l}\text { - Fokl "FF": higher insulin levels; increased risk for IR } \\
\text { - Bsml "bb" and Taql "TT": higher } 25(\mathrm{OH}) \text { D levels }\end{array}$ \\
\hline $\begin{array}{l}\text { Wehr et al. } \\
\text { (2011) [16] }\end{array}$ & Caucasian & $\begin{array}{l}\text { Rotterdam } \\
\text { criteria }\end{array}$ & $\begin{array}{l}\text { PCOS: } 545 \\
\text { Control: } 145\end{array}$ & $\begin{array}{l}\text { Fokl Apal } \\
\text { Bsml Cdx2 } \\
\text { Taql }\end{array}$ & $\begin{array}{l}\text { - Apal "AA": lower testosterone levels } \\
\text { - Cdx2 "AA": lower fasting insulin and HOMA-IR; higher } \\
\text { QUICKI }\end{array}$ \\
\hline $\begin{array}{l}\text { El-Shal et al. } \\
\text { (2013) [20] }\end{array}$ & Caucasian & $\begin{array}{l}\text { Rotterdam } \\
\text { criteria }\end{array}$ & $\begin{array}{l}\text { PCOS: } 150 \\
\text { Control: } 150\end{array}$ & Apal Taql & $\begin{array}{l}\text { - Taql "C" allele: more frequent in obese PCOS women } \\
\text { - Taql "CC" and “TC": higher BMI, AFC, fasting insulin, } \\
\text { HOMA-IR, testosterone, DHEA-S, androstenedione; lower } \\
\text { 25(OH)D levels, QUICKI } \\
\text { - "TaqI C/ Apal C": lower 25(OH)D levels; higher testosterone, } \\
\text { DHEA-S, androstenedione }\end{array}$ \\
\hline $\begin{array}{l}\text { Zadeh-Vakili } \\
\text { et al. (2013) [22] }\end{array}$ & $\begin{array}{l}\text { Western } \\
\text { Asian }\end{array}$ & NIH criteria & $\begin{array}{l}\text { PCOS: } 260 \\
\text { Control: } 221\end{array}$ & Tru9l & - "GA + AA": severe hirsutism and oligo-amenorrhea \\
\hline $\begin{array}{l}\text { Dipanshu et al. } \\
\text { (2015) [31] }\end{array}$ & $\begin{array}{l}\text { Southern } \\
\text { Asian }\end{array}$ & $\begin{array}{l}\text { Rotterdam } \\
\text { criteria }\end{array}$ & $\begin{array}{l}\text { PCOS: } 125 \\
\text { Control: } 82\end{array}$ & Fokl Apal & - Apal “CC": lower estradiol and androstenedione levels \\
\hline $\begin{array}{l}\text { Jedrzejuk et al. } \\
\text { (2015) [29] }\end{array}$ & Caucasian & $\begin{array}{l}\text { Rotterdam } \\
\text { criteria }\end{array}$ & $\begin{array}{l}\text { PCOS: } 92 \\
\text { Control: } 85\end{array}$ & $\begin{array}{l}\text { Fokl Apal } \\
\text { Bsml Taql }\end{array}$ & $\begin{array}{l}\text { - No difference between gene variants and metabolic } \\
\text { parameters in PCOS group }\end{array}$ \\
\hline $\begin{array}{l}\text { Dasgupta et al. } \\
\text { (2015) [27] }\end{array}$ & $\begin{array}{l}\text { Southern } \\
\text { Asian }\end{array}$ & $\begin{array}{l}\text { Rotterdam } \\
\text { criteria }\end{array}$ & $\begin{array}{l}\text { PCOS: } 250 \\
\text { Control: } 250\end{array}$ & $\begin{array}{l}\text { Fokl Apal } \\
\text { Cdx2 Taql }\end{array}$ & $\begin{array}{l}\text { - Fokl “TT": increased risk for infertility, acne, alopecia, } \\
\text { elevated cholesterol levels } \\
\text { - Apal “AA": higher testosterone levels } \\
\text { - Taql “TC": higher levels of FSH, LH, cholesterol } \\
\text { - Taql "CC": higher testosterone } \\
\text { - Cdx2 "GC”: traits like acne, hirsutism, AN, increased } \\
\text { - cholesterol levels } \\
\text { - Cdx2 "AA": higher testosterone levels; risk for infertility }\end{array}$ \\
\hline $\begin{array}{l}\text { Mahmoudi et al. } \\
\text { (2015) [34] }\end{array}$ & $\begin{array}{l}\text { Western } \\
\text { Asian }\end{array}$ & NIH criteria & $\begin{array}{l}\text { PCOS: } 35 \\
\text { Control: } 35\end{array}$ & $\begin{array}{l}\text { Fokl Apal } \\
\text { Bsml Taql } \\
\text { Tru9l }\end{array}$ & $\begin{array}{l}\text { - No relationship between gene variants and insulin } \\
\text { metabolism in PCOS group }\end{array}$ \\
\hline $\begin{array}{l}\text { Kadhim et al. } \\
\text { (2017) [33] }\end{array}$ & $\begin{array}{l}\text { Western } \\
\text { Asian }\end{array}$ & $\begin{array}{l}\text { Rotterdam } \\
\text { criteria }\end{array}$ & $\begin{array}{l}\text { PCOS: } 50 \\
\text { Control: } 50\end{array}$ & Fokl Apal Taql & - Fokl “CC”, Apal “CC”, “CA”, Taql “CC”: higher prolactin levels \\
\hline $\begin{array}{l}\text { Al Thomali et al. } \\
\text { (2018) [21] }\end{array}$ & $\begin{array}{l}\text { Western } \\
\text { Asian }\end{array}$ & $\begin{array}{l}\text { Rotterdam } \\
\text { criteria }\end{array}$ & $\begin{array}{l}\text { PCOS: } 16 \\
\text { Control: } 17\end{array}$ & $\begin{array}{l}\text { Foki Apal } \\
\text { Taql + others }\end{array}$ & - TaqI “CC”: associated with vitamin D levels \\
\hline $\begin{array}{l}\text { Humadi et al. } \\
\text { (2018) [28] }\end{array}$ & $\begin{array}{l}\text { Western } \\
\text { Asian }\end{array}$ & $\begin{array}{l}\text { Rotterdam } \\
\text { criteria }\end{array}$ & $\begin{array}{l}\text { PCOS: } 100 \\
\text { Control: } 100\end{array}$ & Fokl Apal & $\begin{array}{l}\text { - Fokl "FF", Apal “AA": lower levels of vitamin D and } \\
\text { androstenedione }\end{array}$ \\
\hline $\begin{array}{l}\text { Santos et al. } \\
\text { (2018) [32] }\end{array}$ & Caucasian & $\begin{array}{l}\text { Rotterdam } \\
\text { criteria }\end{array}$ & $\begin{array}{l}\text { PCOS: } 191 \\
\text { Control: } 100\end{array}$ & $\begin{array}{l}\text { Apal Bsml } \\
\text { Taql }\end{array}$ & $\begin{array}{l}\text { - Apal "CC": higher risk for Mets; higher systolic blood } \\
\text { pressure, total cholesterol, LDL-c }\end{array}$ \\
\hline $\begin{array}{l}\text { Hamdi et al. } \\
\text { (2018) [39] }\end{array}$ & $\begin{array}{l}\text { Western } \\
\text { Asian }\end{array}$ & $\begin{array}{l}\text { Rotterdam } \\
\text { criteria }\end{array}$ & $\begin{array}{l}\text { PCOS: } 45 \\
\text { Control: } 43\end{array}$ & $C d x 2$ & $\begin{array}{l}\text { - Cdx2 "AA": lower fasting serum glucose, insulin and } \\
\text { HOMA-IR } \\
\text { - Cdx2 "GG": higher LH, LH/FSH ratio; lower } 25(\mathrm{OH}) \text { D levels }\end{array}$ \\
\hline $\begin{array}{l}\text { Song et al. } \\
\text { (2019) [18] }\end{array}$ & Asian & NIH criteria & $\begin{array}{l}\text { PCOS: } 432 \\
\text { Control: } 927\end{array}$ & $\begin{array}{l}\text { Fokl Apal } \\
\text { Bsml Cdx2 }\end{array}$ & $\begin{array}{l}\text { - FokI "AC": increased levels of total testosterone } \\
\text { - Cdx2 "CC": increased level of fasting insulin and HOMA- IR }\end{array}$ \\
\hline $\begin{array}{l}\text { Szafarowska } \\
\text { et al. (2019)[30] }\end{array}$ & Caucasian & $\begin{array}{l}\text { Rotterdam } \\
\text { criteria }\end{array}$ & $\begin{array}{l}\text { PCOS: } 75 \\
\text { Control: } 23\end{array}$ & $\begin{array}{l}\text { Fokl Apal } \\
\text { Bsml Cdx2 }\end{array}$ & $\begin{array}{l}\text { - Fokl "CT", "TT" and Apal "CA", “CC": higher AMH levels } \\
\text { - Apal "AA": higher } 25(\mathrm{OH}) \text { D values }\end{array}$ \\
\hline $\begin{array}{l}\text { Ramezani et al. } \\
\text { (2020) [37] }\end{array}$ & $\begin{array}{l}\text { Western } \\
\text { Asian }\end{array}$ & NIH criteria & $\begin{array}{l}\text { PCOS: } 38 \\
\text { Control: } 40\end{array}$ & Bsml & $\begin{array}{l}\text { - No association between Bsml genotypes and metabolic/ } \\
\text { endocrine parameters }\end{array}$ \\
\hline
\end{tabular}

IR: Insulin resistance; HOMA-IR: Homeostasis model assessment-estimated insulin resistance; QUICKI,: Quantitative insulin sensitivity check index; BMI: Body mass index; AFC: Antral follicle count; DHEA-S: Dehydroepiandrosterone sulfate; FSH: Follicle stimulating hormone; LH: Luteinizing hormone; AN: Acanthosis nigricans; Mets: Metabolic syndrome; LDL-c: Low density lipoprotein-cholesterol; AMH: Anti-Müllerian hormone. 
All in all, studies suggest that higher values of androgen hormones are correlated with Taql "CC" variant in both Caucasian and Asian population [20,27], the same genotype being also associated with vit D levels [20, 21, 26].

\section{PCOS and Cdx2 polymorphism}

Cdx2 polymorphism (rs 11568820) is a guanine to adenine sequence, located in the 1 a promoter area of VDR gene, acting as a transcription factor $[16,24,27]$. Even though $C d x 2$ polymorphism was investigated only in 5 selected articles, it seemed that its variants are associated with IR and insulin sensitivity, yet the results are inconsistent. The findings of a Korean study suggest that $\mathrm{Cdx} 2$ "CC" genotype was associated with increased level of fasting insulin and HOMA-IR in PCOS women, but the association was not statistically significant after multiple linear regressions. However, "AA" genotype was correlated with higher fasting insulin in controls [18] this result being inconsistent with the observations of Wehr et al. who showed that Cdx2 "AA" presented lower fasting insulin and HOMA-IR, with significantly higher QUICKI in PCOS group. The Austrian group found no association of $C \mathrm{dx} 2$ polymorphism with vit $D$ levels or endocrine parameters [16]. Hamdi et al. showed that $C d \times 2$ "AA" genotype presented lower fasting serum glucose and insulin, but also "GG" genotype was predisposed to higher LH levels, with lower vit D values [39].

On the other hand, Dasgupta et al. concluded that Cdx2 "GA" genotype and " $A$ " allele had a significantly higher frequency in cases compared to controls and seemed to confer protection against developing PCOS [27]. In contrast, Szafarowska et al. showed that "GG" genotype had higher frequency in PCOS population [30]. In addition, in Indian population "GG" genotype showed greater frequency for traits like acne, hirsutism, acanthosis and elevate cholesterol, while "GA" variant had relatively higher mean values for testosterone, being at risk for alopecia. Moreover, "AA" genotype was associated with elevated testosterone and "GA" and "AA" genotypes were at higher risk for infertility [27].

\section{PCOS and Tru9I polymorphism}

Tru9l polymorphism (rs 757343) located in intron 8, is an adenosine to guanine polymorphism of VDR gene, less investigated than the aforementioned variants. A study from Iran showed that the combined genotype " $\mathrm{GA}+\mathrm{AA}$ " was significantly associated with increased risk of severity of PCOS phenotype, including severe hirsutism and oligo-amenorrhea. Additionally, "A" allele was associated with disease severity and HOMA-IR had higher values in severe phenotype compared to the mild one, suggesting a possible impact of Tru9l on PCOS pathology [22].

\section{Discussion}

PCOS is a complex multigenic disease, where various genes interact with each other and with environmental factors, influencing the development and the manifestations of the syndrome. Vitamin $D$ is involved in a wide variety of biological processes and it mediates its actions through VDR. VDR is distributed across many tissues, including pancreatic beta cells, skin, parathyroid, pituitary gland or reproductive tissue, taking part in regulation of several endocrine, metabolic or reproductive functions [40].
Vitamin D deficiency is considered to take part in the pathogenesis of insulin resistance related diseases, including obesity and diabetes [41] but the interdependency between PCOS and vitamin $D$ status is still questionable. When analyzing vitamin $D$ impact in lean versus obese PCOS women, the results mainly show that lower serum concentrations are associated with obesity and IR but not with PCOS per se [42]. Moreover, when studying the effects of vitamin D supplements on androgen levels and hirsutism in overweight women with PCOS, recent data suggest that testosterone levels and hirsutism score decreased, while sex hormone binding globulin increased. Furthermore, improvement in the regularity of menstrual cycles was observed, highlighting the beneficial effects of vitamin D when PCOS is correlated with increased body mass index [43].

An aspect to keep in mind is the phenotypic classification of PCOS. The classic phenotypes A and B are associated with more severe features such as increased insulin levels and higher rates of insulin resistance, more pronounced menstrual dysfunction, higher risk for metabolic syndrome and obesity. Phenotype C (the "ovulatory PCOS") usually has intermediate levels of androgen hormones, insulin or prevalence of metabolic syndrome, whereas phenotype D (the "non-hyperandrogenic PCOS") is considered to have the mildest endocrine and metabolic disfunction [2]. Between the articles selected for this paper, only one novel study investigated VDR polymorphisms in phenotype $A$, concluding that the homogeneous classic phenotype is not associated with vitamin $D$ deficiency and VDR gene polymorphism in Caucasian population [29].

\section{Conclusion}

This review summarizes the main findings concerning VDR polymorphisms of vit $D$ receptor and metabolic and endocrine abnormalities in PCOS. The review concluded that VDR gene can be a good candidate for PCOS and the polymorphisms might have an impact on the metabolic and endocrine disturbances in various ethnic populations. Our findings indicated that Apal polymorphism was associated with hyperandrogenism in both Asian and Caucasian population. Moreover, Fokl variant was correlated with metabolic and endocrine parameters especially in Asian population, while a relation between $\mathrm{Cdx} 2$ genotypes and insulin sensitivity was observed in both ethnicities.

The limits of the studies are related to several aspects. First, only a few studies are available in the literature regarding VDR gene polymorphisms and metabolic or endocrine manifestations in PCOS and all the mentioned studies for this review were conducted using restriction fragment length polymorphism method (RFLP). Second, there are many differences in terms of diagnostic criteria, ethnicity, and the lack of dividing patients in specific phenotypes. The variation in the environmental factors or the small sample size of the studied groups determined also inconsistent results. Therefore, further functional studies on various homogeneous populations with larger sample size are needed to confirm the current findings, in order to allow prevention or treatment of PCOS comorbidities. 


\section{Acknowledgements}

The authors wish to acknowledge support from Iuliu Hațieganu University of Medicine and Pharmacy (Doctoral research project no. 2461/85/17.01.2020 Cluj-Napoca, Romania).

\section{Conflict of Interest}

The authors declare that they have no conflict of interest.

\section{References}

[1] Azziz R, Carmina E, Chen Z et al. Polycystic ovary syndrome. Nat Rev Dis Primers 2016; 2: 1-18

[2] Lizneva D, Suturina L, Walker W et al. Criteria, prevalence, and phenotypes of polycystic ovary syndrome. Fertil Steril 2016; 106: 6-15

[3] Reis GVOP, Gontijo NA, Rodrigues KF et al. Vitamin D receptor polymorphisms and the polycystic ovary syndrome: A systematic review. J Obstet Gynaecol Res 2017; 43: 436-446

[4] Bozdag G, Mumusoglu S, Zengin D et al. The prevalence and phenotypic features of polycystic ovary syndrome: A systematic review and meta-analysis. Hum Reprod 2016; 31: 2841-2855

[5] Andrade VH, Mata AM, Borges RS et al. Current aspects of polycystic ovary syndrome: a literature review. Rev Assoc Med Bras 2016; 62: 867-871

[6] Bednarska S, Siejka A. The pathogenesis and treatment of polycystic ovary syndrome: what's new? Adv Clin Exp Med 2017; 26: 359-367

[7] De Leo V, Musacchio MC, Cappelli V et al. Genetic, hormonal and metabolic aspects of PCOS: an update. Reprod Biol Endocrinol 2016; 14: 38

[8] Carvalho LML, Dos Reis FM, Candido AL et al. Polycystic ovary syndrome as a systemic disease with multiple molecular pathways: A narrative review. Endocr Regul 2018; 52: 208-221

[9] Ozdemir S, Ozdemir M, Görkemli $\mathrm{H}$ et al. Specific dermatologic features of the polycystic ovary syndrome and its association with biochemical markers of the metabolic syndrome and hyperandrogenism. Acta Obstet Gynecol Scand 2010; 89: 199-204

[10] Hong JS, Kwon HH, Park SY et al. Cutaneous manifestations of the subtypes of polycystic ovary syndrome in Korean patients. J Eur Acad Dermatol Venereol 2015; 29: 42-47

[11] Feng JG, Guo Y, Ma LA et al. Prevalence of dermatologic manifestations and metabolic biomarkers in women with polycystic ovary syndrome in north China. J Cosmet Dermatol 2018; 17: 511-517

[12] Neven ACH, Laven J, Teede HJ et al. Summary on polycystic ovary syndrome: diagnostic criteria, prevalence, clinical manifestations, and management according to the latest international guidelines. Semin Reprod Med 2018; 36: 5-12

[13] Nyagolova PV, Mitkov MD, Orbetsova MM. Role of vitamin D and adipose tissue hormones in women with reproductive disorders. Folia Med (Plovdiv) 2015; 57: 5-10

[14] Niu YM, Wang YD, Jiang GB et al. Association between vitamin D receptor gene polymorphisms and polycystic ovary syndrome risk: A meta-analysis. Front Physiol 2019; 9: 1902

[15] Liang F, Ren N, Zhang $\mathrm{H}$ et al. A meta-analysis of the relationship between vitamin $\mathrm{D}$ receptor gene Apal polymorphisms and polycystic ovary syndrome. Adv Clin Exp Med 2019; 28: 255-262
[16] Wehr E, Trummer O, Giuliani A et al. Vitamin D-associated polymorphisms are related to insulin resistance and vitamin $D$ deficiency in polycystic ovary syndrome. Eur J Endocrinol 2011; 164: 741-749

[17] Siddamalla S, Reddy TV, Govatati S et al. Vitamin D receptor gene polymorphisms and risk of polycystic ovary syndrome in South Indian women. Gynecol Endocrinol 2018; 34: 161-165

[18] Song DK, Lee $\mathrm{H}$, Hong YS et al. Vitamin D receptor and binding protein polymorphisms in women with polycystic ovary syndrome: A case control study. BMC Endocr Disord 2019; 19: 145

[19] Shi XY, Huang AP, Xie DW et al. Association of vitamin D receptor gene variants with polycystic ovary syndrome: A meta-analysis. BMC Med Genet 2019; 20: 32

[20] El-Shal AS, Shalaby SM, Aly NM et al. Genetic variation in the vitamin D receptor gene and vitamin $D$ serum levels in Egyptian women with polycystic ovary syndrome. Mol Biol Rep 2013; 40: 6063-6073

[21] Al Thomali A, Daghestani MH, Daghestani MH et al. Polymorphic variations in VDR gene in Saudi women with and without polycystic ovary syndrome (PCOS) and significant influence of seven polymorphic sites on anthropometric and hormonal parameters. J Med Biochem 2018; 37: 415-425

[22] Zadeh-Vakili A, Ramezani TF, Daneshpour MS et al. Genetic polymorphism of vitamin D receptor gene affects the phenotype of PCOS. Gene 2013; 515: 193-196

[23] Xavier LB, Gontijo NA, Rodrigues KF et al. Polymorphisms in vitamin D receptor gene, but not vitamin $D$ levels, are associated with polycystic ovary syndrome in Brazilian women. Gynecol Endocrinol 2019; 35: 146-149

[24] Vasilovici AF, Grigore LE, Ungureanu L et al. Vitamin D receptor polymorphisms and melanoma. Oncol Lett 2019; 17: 4162-4169

[25] Uitterlinden AG, Fang Y, Van Meurs JB et al. Genetics and biology of vitamin D receptor polymorphisms. Gene 2004; 338: 143-156

[26] Mahmoudi T. Genetic variation in the vitamin D receptor and polycystic ovary syndrome risk. Fertil Steril 2009; 92: 1381-1383

[27] Dasgupta S, Dutta J, Annamaneni S et al. Association of vitamin D receptor gene polymorphisms with polycystic ovary syndrome among Indian women. Indian J Med Res 2015; 142: 276-285

[28] Humadi EH, Showman HA, Al-azzawie RMHF. Association of vitamin-D receptor gene polymorphisms (Fokl and Apal) and vitamin D serum levels in a sample of Iraqi women with polycystic ovary syndrome. Indian J Public Health Res Dev 2018; 9: 867-874

[29] Jedrzejuk D, Łaczmański Ł, Milewicz A et al. Classic PCOS phenotype is not associated with deficiency of endogenous vitamin $D$ and VDR gene polymorphisms rs731236 (Taql), rs7975232 (Apal), rs1544410 (Bsml), rs10735810 (Fokl): a case-control study of lower Silesian women. Gynecol Endocrinol 2015; 31: 976-979

[30] Szafarowska M, Dziech E, Kaleta B et al. Anti-Müllerian hormone level is associated with vitamin $D$ receptor polymorphisms in women with polycystic ovary syndrome. J Assist Reprod Genet 2019; 36: 12811289

[31] Dipanshu S, Chakravorty R. Genetic polymorphism in the vitamin D receptor gene and 25 -hydroxyvitamin $D$ serum levels in East Indian women with polycystic ovary syndrome. J Mol Biomark Diagn 2015; 6: 247

[32] Santos BR, Lecke SB, Spritzer PM. Apa-I polymorphism in VDR gene is related to metabolic syndrome in polycystic ovary syndrome: A cross-sectional study. Reprod Biol Endocrinol 2018; 16: 38

[33] Kadhim S], Abdul-hassan IA. Correlation between vitamin D receptor gene polymorphisms and levels of some hormones in Iraqi infertile women with polycystic ovary syndrome. Iraqi J Biotechnol 2017; 16: 104-113

[34] Mahmoudi T, Majidzadeh-AK, Farahani $\mathrm{H}$ et al. Association of vitamin $D$ receptor gene variants with polycystic ovary syndrome: A case control study. Int J Reprod Biomed 2015; 13: 793-800 
[35] Bagheri M, Rad IA, Jazani NH et al. Lack of association of vitamin D receptor Fokl (rs10735810) (C/T) and Bsml (rs1544410) (A/G) genetic variations with polycystic ovary syndrome risk: a case-control study from Iranian Azeri Turkish women. Maedica (Bucur) 2012; 7: 303-308

[36] Ranjzad F, Mahban A, Shemirani Al et al. Influence of gene variants related to calcium homeostasis on biochemical parameters of women with polycystic ovary syndrome. J Assist Reprod Genet 2011; 28: 225-232

[37] Ramezani N, Ostadsharif M, Nayeri H. Association of Bsml variant of vitamin $D$ receptor gene with polycystic ovary syndrome: A case-control study. Int J Reprod BioMed 2020; 18: 877-884

[38] Bagheri M, Abdi RI, Hosseini JN et al. Vitamin D receptor Taql gene variant in exon 9 and polycystic ovary syndrome risk. Int J Fertil Steril 2013; 7: 116-121

[39] Hamdi RA, Abdul-Qahar ZH, Ahmed S] et al. Assessment of vitamin D receptor gene polymorphism in Iraqi women with polycystic ovary syndrome. J Clin Diagnostic Res 2018; 12: 27-30
[40] Wang Y, Zhu J, DeLuca HF. Where is the vitamin D receptor? Arch Biochem Biophys 2012; 523: 123-133

[41] Szymczak-Pajor I, Śliwińska A. Analysis of association between vitamin D deficiency and insulin resistance. Nutrients 2019; 11: 794

[42] Hahn S, Haselhorst U, Tan S et al. Low serum 25-hydroxyvitamin D concentrations are associated with insulin resistance and obesity in women with polycystic ovary syndrome. Exp Clin Endocrinol Diabetes 2006; 114: 577-583

[43] Al-Bayyari N, Al-Domi H, Zayed F et al. Androgens and hirsutism score of overweight women with polycystic ovary syndrome improved after vitamin D treatment: A randomized placebo controlled clinical trial. Clin Nutr 2021; 40: 870-878 